\title{
Turning ideas into products: subjective well-being in co-creation
}

\begin{abstract}
New services, like fabrication spaces, 3D printer rentals and virtual marketplaces, have made it easier for empowered consumers to co-create innovative products without almost any involvement of traditional companies. Adopting a consumer-grounded view, this work takes a step forward from the existing service literature by investigating the link between psychological motives and happiness in co-creation. Specifically, the study measures how community affiliation, personal growth, and utilitarian motives are predictors of subjective well-being. The results illustrate that community affiliation and personal growth motives predict high scores of subjective well-being, while utilitarian motives do not. In addition, empowered consumers who co-create with others are happier than consumers who create alone. This indicates that direct interactions are not only a powerful platform for service co-creation, but are also predictors of subjective well-being. We discuss the implications for traditional companies and for decision makers regarding the benefits offered by digital fabrication services.
\end{abstract}

Keywords: co-creation, psychological motives, subjective well-being, service design, open innovation spaces 


\section{Introduction}

The diffusion of personal fabrication means that consumers use digital fabricators, e.g. 3D-printers or laser cutters, at home, or in places that provide services able to help people to manufacture physical artifacts, i.e. FabLabs. Digital fabrication is attracting a variety of enthusiastic claims that emphasize how a radical innovation is taking place. According to these perspectives, the public access to personal fabrication tools, software and databases of digital designs is leading to what has already been called a new industrial revolution (Berman, 2012), extending the digital revolution of ICTs and social media to the material world. Personal fabrication allows the democratization of mass manufacturing and commercial services for the benefit of consumers and society contributing to a post-consumer sustainable society. A new scenario where consumers can design and produce their own objects is emerging. While last generations have experienced a loss in their capacity to make/repair products, personal fabrication helps consumers to take over chores usually done by professionals. By experimenting with self-sufficiency, individuals are recognizing their own power through everyday action.

Digital fabrication enables grassroots innovation that spreads collaboratively through networks involving social media and physical meeting places. The technological innovation is boosted by the willingness of people to participate in the co-creative process.

This study focuses on FabLabs, which are open innovation spaces (Chesbrough, 2003), where empowered consumers can co-create innovation by directly interacting with each other. In service marketing research the interaction concept is a key construct. As suggested by Grönroos (2011) and by Grönroos and Voima (2013), co-creation of value can take place only if direct interactions between the service provider and the consumers occur. The present work explores the role of interaction in consumers' well-being.

The main goal of the study is to fill a research gap in service research and applied psychology, by 
analyzing the psychological motives in co-creation, and their relation to subjective well-being. In service marketing, empirical studies of consumer co-creation have typically focused on the benefits to companies, such as increasing productivity (e.g. Bettencourt, 1997; Hoyer et al., 2010; Janeschek et. al., 2013) and gaining customer loyalty (e.g. Auh et al., 2007; Polo Peña et al., 2014) but almost no theoretical attention has been paid to the implications of co-creation on consumer themselves. The constructs of subjective well-being and their antecedents have been topics of recent attention in the applied psychology literature (Judge et al., 2010). By bridging the link between consumer cocreation and consumer subjective well-being (SWB), this study extends Guo et al.'s (2013) work which tested co-production as an antecedent of SWB. The recent movement of transformative consumer research specifically advocates for research that investigates consumer's subjective wellbeing (Rosenbaum et al., 2011; Ostrom et al., 2010, Anderson et al., 2013, Ozanne, 2011). While a positive association has been assessed between innovation and subjective well-being (Dolan and Metcalfe, 2012), subjective well-being in co-creation has yet not been analyzed.

We propose that open innovation space services are an important mean to consumer empowerment. Consumers not only are responsible for the choices that affect their consumption activities but work for themselves. Mental states are important to individuals, managers, and policy-makers. Despite Transformative Service Research focuses on how service providers and organizations help create positive changes and improvements in the people's well-being, co-creation and its relation to consumers' subjective well-being has not been investigated. Open innovation space services are here interpreted as services that by empowering consumers are able to enhance consumers' wellbeing.

The development and deployment of open innovation services, may be read under a transformative service lens in a number of ways. At an individual level, consumers learn a fundamentally empowering lesson: they can be too the creator of things. At a collective level, open innovation contexts develop activities with local communities to address unmet needs (designing and creating from toys to solar panels and eco-houses). This is achieved by boosting the creativity of those with 
the least resources (Anderson et al., 2013).

Together they create holistic service experiences where customers are able to experiment, with ideas and techniques, risk mistakes and hold-ups.

As Anderson et al.'s (2013) framework illustrates, consumers' well-being can be affected at different levels - namely, individual, collective, and the broader ecosystem. While open innovation contexts are affecting all three levels, we will be focusing on the individual one, by incorporating SWB, a measure that is advocated to be more effective, compared to consumer satisfaction for example, in capturing issues central to transformative service research (Anderson et al., 2013).

The approach that sees in digital fabrication a democratization opportunity that includes all of us broadens von Hippel's initial point of view, for whom innovation was generated by leading users, (von Hippel, 2005), a market economy rhetoric which was excluding the majority of population.

Fabrication spaces and services boost co-creation or what are defined open collaborative innovation projects (Baldwin and von Hippel, 2011) between empowered consumers. Within the service research domain, the service-dominant (S-D) logic (Vargo and Lusch, 2008) proposes that the roles of producers and consumers are not distinct, meaning that value is always co-created, jointly and reciprocally, in interactions among providers and beneficiaries through the integration of resources and application of competences (Vargo et al., 2008). Taking a step forward from this approach, we can suggest that consumers, facilitated by digital fabrication services, can act both as developers and marketers, contributing to the success of new products in terms of functional characteristics and market access, due to their role as opinion leaders and trendsetters.

\section{Why consumers co-create? What's behind co-creation}

Despite most studies on consumer participation have largely focused on its economic implications for the company, contributions from the psychology field are available and mainly take into account motivational or behavioural constructs (Olsen \& May, 2013; Etgar, 2008). In agreement with Olsen and May (2013), marketers should recognize that whether and how consumers participate in value- 
creation activity is explicitly a result of consumers' psychological factors. Thus, the main questions are: why do people commit their time to projects from which they are unlikely to get direct financial benefit? What drives consumers' creation?

Füller (2010) identified ten categories of motives: intrinsic playful task, curiosity, self-efficacy, skill development, information seeking, recognition (visibility), community support, making friends, personal needs (dissatisfaction), and compensation (monetary reward).

The intrinsic motivations, where individuals create for the sake of creation, include enjoyment, selfexpression, altruism, generalized reciprocity, and gift-giving attitude (Füller, 2010). For example, Frank and Shah (2003) argue that many innovators in the sports equipment consumer communities enjoy working with others to develop their hobby products. Do-It-Yourself is powerful because it taps into the passion and creativity of individuals around the world. Extrinsic motives focus, instead, on the potential outcomes, which are separated from the activity itself, and in co-creation they often refer to economic rewards, and career prospects.

It is possible to synthetize the drives described above in three different taxonomies: personal growth motives, community affiliation motives, and utilitarian motives.

(1) Personal growth motives relate to feelings of achievement, self-expression (Ho \& Dempsey, 2010) and are consistent with Maslow's seminal work (1987) on motivation in relation to the higher level of needs. Self-actualization needs are defined as the full realization of one's potentials. The word derives from the idea that each individual has a lot of hidden potentialities: talents or competences he or she could develop, but which have as yet not come to the surface. Selfactualization may be called a growth motive (Heylighen, 1992) in the sense that deviations from the previously reached equilibrium state are not reduced, but enhanced. People driven by this motive are eager to undergo new experiences, learn new ideas and skills, try out new things, experimenting and developing creativity.

(2) Community affiliation motives refer to the "other" and can be considered a pervasive drive to form and maintain interpersonal relationships (Baumeister \& Leary, 1995). They relate to the social 
benefits derived from establishing and maintaining contact with other people such as social support, friendship, and intimacy. Several studies have shown that many participants join virtual communities mainly to dispel their loneliness, meet like-minded others, and receive companionship and social support (e.g., McKenna \& Bargh, 1999). Altruism, or the willingness to contribute to the welfare of other people, is another motivation (Osterloh and Rota, 2007) included in this category.

(3) Utilitarian motives are structured and aimed at achieving a specific purpose. Utilitarian motivation involves satisfying functional and has often been characterized as task related and rational (Batra \& Ahtola, 1991). Consumers with a utilitarian motive are outcome-focused, allocating effort to activities that are means to achieving an end (Deci \& Ryan, 1985). They have a clearly definable goal hierarchy (Novak, Hoffman \& Duhachek, 2003), adopting the most efficient linear routes to achieve their goal. Of special relevance from a marketing perspective is the research carried out by Dholakia et al. (2004) who show that individuals characterized by a goal-directed fashion derive from virtual communities a set of values of which purposive values are defined "the value derived from accomplishing some pre-determined instrumental purpose" (Dholakia et al., 2004: 244).

While motives have not been directly linked to well-being, the construct of values has (Sheldon et al., 2010). Values influence how we perceive stimuli and incentives in the environment, how we assess the situations and events we experience, and which goals and intentional efforts we choose to pursue from day to day (Feather, 1992). "Intrinsic', values (community affiliation, community feeling, self-acceptance, personal growth and affiliation) are said (Sheldon et al., 2010) to more directly satisfy people's basic psychological needs and foster their growth and thriving, whereas the “extrinsic" values (financial success, social achievement) are said to be less directly satisfying of needs and growth strivings, tending instead to foster excessive ego involvement and social comparison (Kasser, 2002). Specifically, those with relatively stronger extrinsic values have been shown to be less happy and less well-adjusted compared to those who give greater weight to the intrinsic values, according to both self-report and interview measures of adjustment (Kasser, 2002). 
Because motives (the "why") and the content of values (the "what") of goal pursuits have been shown to be largely independent of one other (Sheldon et al., 2004), this study aims to understand if the relation between values (the "what") and well-being can be applied to the relation between motives (the "why") and well-being in these co-creation service processes.

\section{Anatomy of subjective well-being}

Psychological SWB has received an increasing attention in the scientific community and among practitioners (e.g., Abbott et al., 2006; Lavasani et al., 2011). Transformative service research, as well, advocates the use of SWB as a powerful measure able to capture important issues in service research (Anderson et al., 2013). While SWB has in past been investigated in relation to innovation (Dolan and Metcalfe, 2012), to technological access and affluence (Graham and Nikolova, 2013; Kavetsos and Koutroumpis, 2011), the service co-creation research stream has still not adopted this measure.

The field of SWB comprises the scientific analysis of how people evaluate their lives — both at the moment and for longer periods such as for the past year. These evaluations include people's emotional reactions to events, their moods, and judgments they form about their life satisfaction, fulfillment, and satisfaction with domains such as marriage and work. Thus, SWB concerns the study of what lay people might call happiness or satisfaction. General reviews of SWB can be found in Argyle (2001), Diener (1984) and Diener et al. (1999). SWB can be measured by global evaluations of life overall - how well life is going for each individual (Dolan et al., 2008), and also by experiences of daily affect - an assessment of affect over a specified duration of time (Kahneman et al., 2004).

One universalistic measure derives from humanistic theories of psychology. Ryff (1989) relied on humanism in asserting that there are six universal needs - for autonomy, growth, relationships, purpose in life, environmental mastery, and self-acceptance. Ryff found that the degree to which people reported fulfilling these needs correlated with their reported life satisfaction. 
The foregoing literature review suggests testing the presence of a potential relation between the three above described motives and the dimensions that define SWB.

We hypothesize that SWB is positively predicted by co-creation's community affiliation and personal growth motives, because behaviours such as sharing projects, ideas and actively cocreating physical objects appear to be determinants when it comes to attending an open innovation context. As intrinsic values are said (Sheldon et al., 2010) to satisfy basic psychological needs, we propose:

H1a: Personal growth motives in co-creation are positive predictors of subjective well-being H1b: Community affiliation motives in co-creation are positive predictors of subjective wellbeing

More possessions are generally assumed to lead to greater happiness and satisfaction in life. Consumption has become a culturally accepted means of seeking success, happiness, and the populist notion of a good life (Burroughs and Rindeisch, 2002). However, a vast number of authors have found that well-being and happiness are negatively affected by materialism (e.g., Kasser, 2002; Karabati and Cemalcilar, 2010), because people's self-esteem, emotions, feelings of attractiveness, and body image are negatively affected. Also Burroughs and Rindfleisch (2002) found that materialism was negatively correlated with collective-oriented values such as benevolence, and universalism, elements that appear present in an empowered consumer context. Finally, extrinsic values (e.g. financial success) are said to be less directly satisfying of psychological basic needs (Sheldon et al., 2010).

H1c: Utilitarian motives in co-creation are negative predictors of subjective well being All this leads to a further hypothesis. Community affiliation is strongly related with collaboration 
because both constructs are based on the idea that consumers express themselves establishing a world where joint imagination and reasoning coexist (Kale, 2004). Consistently with H1b, we posit that, in an open innovation context, subjects who generate artifacts in collaboration with others are happier than the ones who create alone.

More formally:

H2: Empowered consumers who collaborate with others are happier than empowered consumers who create alone

\section{Method}

We devote our analysis to the so-called Maker community, in specific to members of FabLabs, who are a very strong virtual and offline group of empowered consumers in the open innovation context. A FabLab (Fabrication Laboratory) is a small-scale workshop offering (personal) digital Fabrication tools and services. FabLabs provide facilities that bring people to collaborate in Do-It-Yourself projects where they learn together and co-create - from toys to solar panels and eco-houses - and use social media to connect to open-source designs and tutorials. FabLabs are considered as democratic spaces that offer a supportive platform for such amateur empowerment. According to Troxler (2010) this happens in a number of ways: encouraging hands-on learning and experimenting, keeping example of previous experiences to show to other users, facilitating connections with other relevant members of the local and international community and supervising the whole creative process if necessary. By offering flexible, dynamic and co-created services with customers, FabLabs represent a powerful example of service design that involves the orchestration of clues, places, processes, and interactions.

Open innovation contexts don't only provide equipment and tangible resources to consumers. Rather, from a service perspective, they facilitate direct interactions between empowered consumers. Differently from traditional rental services, such as hotels or car rentals, or even more innovative ones, such as car sharing, open innovation spaces are characterized by a strong sense of 
brand community. Zip Car's consumers, the world's largest car-sharing company, resist any cocreation efforts from the company to engage in community building or identity connection that go beyond market exchange. Car sharing is similar to other market exchange in the sense that it is motivated largely by self-interest and utilitarianism (Bardhi and Eckhardt, 2012). Differently, cocreation in open innovation contexts appears to be driven by different kinds of motivations.

There are currently over 150 FabLabs in 20 countries, with many more on the planning stage. We have focused on FabLab users because it is a highly active online community, which also meets and socially interacts in a physical place so to share technological tools and specific knowledge. This study was carried out on a potential sample of 580 active members of FabLab communities from two countries, Italy and Spain, through an online link in the website of the FabLabs of Turin and Barcelona. The online survey was administered with Qualtrics software in June and July 2013. Participation was voluntary in both groups. The response rate was around 25 percent, in line with the general response rate by email invitation (Anseel et al., 2010), with a final collected sample of 142. Only 129 respondents passed data-quality checks, 72 for the Italian sample and 57 for the Spanish sample. The excluded respondents consisted of those who failed to pass the internal Kendall's tau test for consistency. Reasons for a low Kendall's tau coefficient could be low motivation and fatigue. Once participants accessed the link they were informed that they were going to answer an online survey. After the whole process, we asked to leave comments, if any. An Amazon gift of 100Eu was provided to three randomly chosen respondents.

Regarding the sociodemographic characteristics of the sample, we specifically collected data regarding gender, education, and age as done in Diener (1999), in order to assess the consistency of the two samples and the possible impact in terms of subjective well-being. A $43 \%$ of females, with an average age of 33 for the Spanish sample and a 22\% of females with an average age of 30 for the Italian sample, composed the final sample. The two cultural samples did not statistically differ in terms of gender representation, level of education and age.

\section{Construct Measurements}


The scale we adopted (Ryff, 1989) is one of the most widely applied measures of psychological SWB in clinical and general samples, used for gender, age, marital status, level of education, health, and other aspects of SWB. The scale has been validated and used by several authors in the past and more recently (Clarke et al., 2001; Keyes et al. 2002; Ryff, 1989; Ryff \& Keyes 1995, Siringatti et al., 2012). It specifically refers to what Ryff (1989) terms eudaimonic well-being, which emphasizes the realization of potential. According to Anderson et al. (2013) this definition is consistent with the conceptualization of quality of life as the development of human capabilities and freedom.

The theoretical considerations to elicit each of the six constructs of SWB in the 9-items scale, autonomy, growth, relationships, purpose in life, environmental mastery, and self-acceptance, can be found in Ryff (1989).

Aside from the constructs of subjective well-being, we needed to operationalize the independent variables (i.e. motives, see Table 1). A pre-test research phase was carried out interviewing Italian and Spanish FabLabs' Directors, with the aim to design appropriate items of the survey able to measure a set of possible drives to co-creation in the specific community under analysis. Personal growth motives include the following concepts: self-expression; creativity boost; hacking; people empowerment; passion; learning new things; experimenting. Under the taxonomy of Community affiliation motives the following concepts were measured: sharing projects; social relations improvement by creating in a group; peer-to-peer support; open-source culture; the willingness to include less skilled people in the community; whether personal fabrication is able to stimulate an alternative economy (as a powerful consequence of community's activities). Utilitarian motives refer to: customization of products; entrepreneurial goal; financial benefits; prototypes useful for professional reasons; making objects as spare parts. While Personal growth and Utilitarian motives include statements that more directly relate to reported behaviours, the statements referring to Community affiliation motives intend, aside from measuring the desire to form and maintain interpersonal relationships, to capture an attitude towards a changing cultural paradigm. Therefore 11 
the questions aim to measure the willingness of Makers towards change, and their desire to open the community to individuals and groups from different backgrounds and skills. A total of 21 questions regarding the different motives were chosen and administered in the questionnaire. All the items were presented on a 6-point Likert scale.

Based on the literature described above, in Table 1 the authors propose the different items used to measure the presence and the extent of the different motives. As a check of robustness, some questions were presented in reverse scale.

Table 1. Items used to elicit the 3 different motives

\begin{tabular}{|c|c|}
\hline I attend a Fab Lab out of passion & $\begin{array}{l}\text { PERSONAL } \\
\text { GROWTH } \\
\text { MOTIVES }\end{array}$ \\
\hline I attend a Fab Lab because I enjoy learning new things & \\
\hline I make objects at a Fab Lab without any specific purpose & \\
\hline I attend a Fab Lab because I want to experiment & \\
\hline Fab Labs allow people' empowerment & \\
\hline Fab Labs boost individual creativity & \\
\hline A Fab Lab is a Hackerspace & \\
\hline I attend a Fab Lab because I enjoy sharing my projects with others. & $\begin{array}{l}\text { COMMUNITY } \\
\text { AFFILIATION } \\
\text { MOTIVES }\end{array}$ \\
\hline By creating in a group, my social relationships improve & \\
\hline Digital fabrication stimulates an alternative economy & \\
\hline In the near future many products will be produced at home & \\
\hline Community is the driver of a Fab Lab & \\
\hline Fab Labs are based on an Open Source culture & \\
\hline Fab Labs should collaborate more with traditional companies & \\
\hline Fab Labs should be used by more people without special skills & \\
\hline Peer-to-peer support is crucial in Fab Labs & \\
\hline $\begin{array}{l}\text { Connecting online, sharing knowledge/collaborating/supporting is important for digital } \\
\text { fabrication a... }\end{array}$ & \\
\hline
\end{tabular}




\begin{tabular}{|l|l|}
\hline I engage in Fab Labs activities for financial benefits & $\begin{array}{l}\text { UTILITARIAN } \\
\text { MOTIVES }\end{array}$ \\
\hline I make prototypes at a Fab Lab which are useful for my work & \\
\hline I make objects at a Fab Lab that I want to market & \\
\hline I make objects at a Fab Lab as spare parts & \\
\hline
\end{tabular}

\section{Results}

Table 2 shows significant correlations and descriptive statistics across the six constructs of SWB, our dependent variable. The operationalization used to quantify each construct was the following: starting from the 9-items used to elicit the construct itself we compounded an arithmetic average of the 9-items to create a single value for that dimension at individual level. This methodology to aggregate the questions was proposed by Ryff (1989). All the presented correlations across measures of SWB are significant except the relation between EM and PRO and between EM and PG. Autonomy was excluded from correlations because not significantly related with any other dimensions. This finding is consistent with Ruini (2003). Stemming from these results, SWB was operationalized in the empirical analysis as a weighted average of the five inter-related constructs of SWB.

Table 2. Significant correlations and descriptive statistics $(\mathbf{n}=129)$

\begin{tabular}{|l|l|l|l|l|l|l|}
\hline & Self-acceptance & $\begin{array}{l}\text { Purpose in } \\
\text { life }\end{array}$ & $\begin{array}{l}\text { Positive } \\
\text { relations } \\
\text { with others }\end{array}$ & $\begin{array}{l}\text { Personal } \\
\text { growth }\end{array}$ & $\begin{array}{l}\text { Environmental } \\
\text { mastery }\end{array}$ & Autonomy \\
\hline Self-acceptance & 1 & & & & & \\
\hline Purpose in life & $0.5339^{*}$ & 1 & $0.2715^{*}$ & 1 & & \\
\hline $\begin{array}{l}\text { Positive } \\
\text { relations with } \\
\text { others }\end{array}$ & $0.3339^{*}$ & $0.2095^{*}$ & $0.2049 *$ & 1 & & \\
\hline $\begin{array}{l}\text { Personal growth } \\
\text { Environmental } \\
\text { mastery }\end{array}$ & $0.3831^{*}$ & $0.4658^{*}$ & 0.092 & -0.0128 & 1 & \\
\hline Average & 3.75 & 3.98 & 4.12 & 4.26 & 3.77 & 3.88 \\
\hline
\end{tabular}




\begin{tabular}{|l|l|l|l|l|l|l|}
\hline SD & 1.30 & 1.14 & 1.33 & 1.17 & 1.28 & 1.30 \\
\hline
\end{tabular}

$* p<0.05$

To test for hypotheses 1a, 1b and 1c, the paper posits an hedonic model tested with OLS regression where the level of subjective well-being is predicted by three independent variables: Community affiliation motives, Personal growth motives and Utilitarian motives. The use of linear regression relationships when dealing with determinants of subjective well-being data is wide (Graham and Nikolova, 2013). In the regression model we included, as control variables, the level of education, the level of engagement, age and gender. The level of engagement was operationalized as the number of time Makers attended a FabLab. Figure 1 shows the simple but yet original conceptual framework investigated.

\section{Figure 1. Conceptual model to measure partial effects of the different motives on subjective} well-being

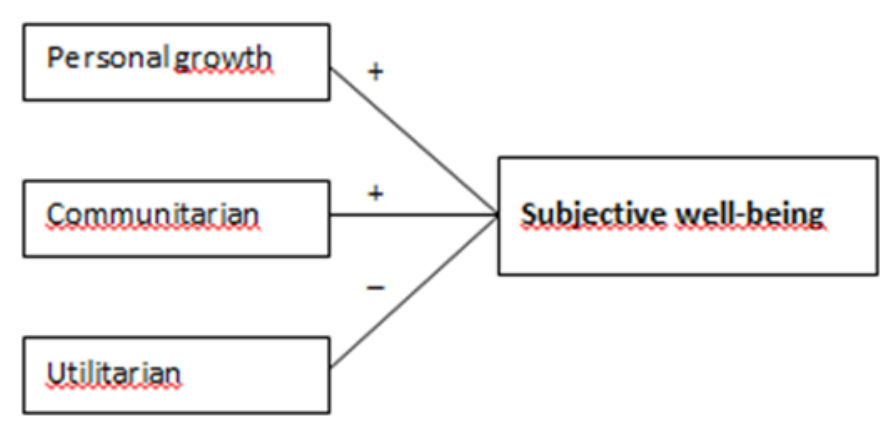

Table 3 presents the empirical test of the above model with two alternative specifications, excluding and including the control variables, respectively. 
Table 3. Regression analysis

\begin{tabular}{lll}
\hline VARIABLES & $\begin{array}{l}(1) \\
\text { subjective } \\
\text { well-being }\end{array}$ & $\begin{array}{l}(2) \\
\text { subjective } \\
\text { well-being }\end{array}$ \\
\hline personal_growth & $0.30^{*}$ & $0.33^{*}$ \\
& $(0.18)$ & $(0.19)$ \\
comunitarian & $0.47^{* *}$ & $0.52^{* * *}$ \\
utilitarian & $(0.18)$ & $(0.191)$ \\
education & -0.16 & -0.16 \\
& $(0.11)$ & $(0.121)$ \\
engagement & & 0.07 \\
age & & $(0.111)$ \\
& & -0.02 \\
gender & & $(0.0722)$ \\
& & 0.01 \\
constant & & $(0.0113)$ \\
& & -0.23 \\
Observations & $5.96^{* * *}$ & $(0.202)$ \\
R-squared & $(1.12)$ & $(1.39)$ \\
\hline Notes: The & & 129 \\
& 129 & 0.13 \\
\hline
\end{tabular}

Notes: The level of education is a categorical variable, which is equal 1 when the level of education is elementary school, 2 when the level of education is secondary school, 3 when it is high school, 4 when it is undergraduate, and 5 when it is graduate school. The goodness of fit statistic reported is the R-squared.

$* p<0.05, * * p<0.01, * * * p<0.001$

The results of the analysis confirm $\mathrm{H} 1 \mathrm{a}$ and $\mathrm{H} 1 \mathrm{~b}$, suggesting that community and personal growth motives are positively predictors of subjective well-being. The result is less clear for utilitarian motives (H1c): the negative sign of the relationship is coherent with the above framework but this result is not significant. It has to be noted that the goodness of the model, by means of R-squared, is pretty low (0.10).

This simply means that, although strongly influenced by these variables, subjective well-being depends reasonably also on other variables, e.g., individual heterogeneity. The second specification shows that the result tend to remain stable after controlling for our control variables, the level of education, the level of engagement, age and gender. This second specification presents an slightly improved goodness of fit. As suggested in Woodside (2013), the study presents also a robustness check with two sub-samples of equal dimension $(n=64)$, obtained by splitting the number of participants in two. The correlation between predicted and actual scores using the estimates from 
the second sub-sample to predict the scores of the first sample and using the estimates from the first sub-sample to predict the scores of the second sample are fairly good ( 0.44 and 0.48 , respectively) and both significant at $10 \%$.

To measure H2, the impact of collaboration on happiness in terms of SWB, we split the sample in two, high and low SWB, based on the mean value of SWB $(\mathrm{M}=3.95 ; \mathrm{SD}=0.75)$, and we investigated how these two groups relate to Community affiliation motives. A two-way analysis of variance yielded a main effect for Community affiliation motives, $\mathrm{F}(1,127)=3.93, \mathrm{p}<.05$, such that the average level of Community affiliation motives was significantly higher for people in the high SWB condition than people in the low SWB condition.

We also measured whether the effect of Community affiliation, Personal growth and Utilitarian motives differs across our cross cultural dimension. An analysis of the results using ANOVA indicated that Community affiliation and Personal growth motives are significantly different between Italy and Spain, F $(1,127)=7.88, \mathrm{p}<.01$, being higher in Spain.

\section{Discussion}

While SWB is certainly the result of different variables, this study confirms that the selected variables (community affiliation and personal growth motives) are predictors of SWB.

The regression analysis allows to make inferences on $\mathrm{H} 1 \mathrm{a}$ and $\mathrm{H} 1 \mathrm{~b}$, confirming our theory on the positive impact of community and personal growth motives on SWB.

Despite the data does not support statistically the negative relation between utilitarian motive and well-being (H1c), the direction of the effect is aligned to the expected direction.

Utilitarian motives are, in fact, drives of low scores in well-being, but this relation is not significant. This group is functional and task-oriented in the expectations of open innovation contexts' services. The Utilitarian group is generally less satisfied after having attended an open innovation context, probably because this group would appreciate different kinds of services, such as being able to market their artifacts. As discussed in the theoretical part, the utilitarian type is, in fact, focused on 
financial benefits, entrepreneurial goals, and usefulness in their work. This group also shows a more preservative attitude towards the current state of affairs, presenting a more narrow-minded attitude towards opening the community to less skilled people and believing that in the future digital fabrication will be adopted more massively.

The findings support $\mathrm{H} 2$, which states that Makers who collaborate with others are happier than Makers who create alone. The research shows that if we split the participants according to higher/lower scores in SWB we are able to infer two heterogeneous approaches to co-creation during FabLabs' services use.

The interactions which characterized Community affiliation and Personal growth groups are therefore not only necessary for value service co-creation, as pointed out by Grönroos (2011), but they also become predictors of SWB. Of interest for the service literature, we found that these makers strongly believe in the open-source culture, and that personal fabrication is able to contribute to a thriving and alternative economy. These Makers express a positive and open attitude towards change, willing the community not only to provide access to direct personal manufacturing equipment but becoming a community that also empowers individuals and groups from different backgrounds and skills. "Happier" makers are also driven by Personal Growth motives, which find in personal fabrication stimuli for self-achievement, creativity development, experimentation, and passion. The findings are even more robust for the Spanish sample, which shows higher levels of SWB for the Community affiliation members.

\section{Implications}

Different implications can be drawn from our study. Academic and management marketing researches should take into consideration that although Makers are still a minority of the population, as manufacturing technologies and online sharing grow, they may turn out to be the early adopters of technology and practices that will eventually be taken up by the larger population. This is what has happened for Digital Creation, which has, in fact, become a mainstream trend 
(Cova \& Dalli, 2009), with millions of consumers, termed generation $C$ (where the $\mathrm{C}$ representing "content") that upload pictures, movies, blogs, and music. In this paper we describe a minority of people that are transforming the notion of a conceptual/abstract idea of creativity in a very practical one (manufacturing goods), through the services offered by open innovation spaces. In specific, the findings contribute to service research in a number of ways. First, despite service literature on service co-creation has already taken a customer-grounded view, it still contemplates a strong role of traditional companies. The present work takes a step forward, exploring an empowered community that creates value by generating its own concepts, without almost any interactions with the company, and as Cova and White state (2010: 265) "this value is therefore captured directly by the community. Companies gain no value directly but must face a risk of indirect competition". Empowered consumers, ever more creative, skilled, passionate, independent, self-governing are creating a new eco-system that doesn't seem to be under the direct control of traditional brands: we are dealing with taxonomy of co-creation that includes people, belonging to different backgrounds, that design, manufacture, market products in non-conventional ways, creating new brands of their own.

Second, the links made between co-creation and well-being, have rarely been made. Our findings expand Guo et al.'s (2013) work, which tested co-production as an antecedent of well-being. Our results integrate these findings investigating the specific dimensions (i.e. motives) under which cocreation increases subjective well-being. More specifically, we show how open innovation contexts' services are able to affect consumers' SWB, giving new insights to the service research literature. Third, the interactions between consumers, boosted by open innovation space services, not only are the platform for service co-creation, as pointed out by Grönroos (2011) and by Grönroos and Voima (2013), but are also predictors of SWB.

Digital fabrication represents therefore a new kind of competition for traditional companies, but it certainly could offer new opportunities. As Community Affiliation motives tend to be the strongest in people with high levels of SWB, companies should propose tools to trigger them and design 18 
platforms where people create with others. Marketing strategies should also be able to boost individual's perception of experimenting something new in order to satisfy Personal Growth motives. Our study offers useful insights for decision makers as well for whom mental states are important. The results assist them in understanding that well-being is intended as an important end goal and that Community Affiliation motives and Personal Growth motives in co-creation services can be very gratifying drivers, doing things just for the pleasure of doing them, but with others. Decision makers who are able to bring people together will help them enhance their well-being and the creation of an always larger network of local FabLabs, or mini FabLabs (in schools, libraries), which could have a powerful collective and social impact.

Although not tested directly with a treatment group, the average level of SWB in this community of people is higher than the average level of subjective well-being in the countries where we run the study (Rice \& Steele, 2004). Therefore, with an appropriate level of cautiousness, we can claim that these services have a positive impact on average on the subjective well-being of their participants.

\section{Limitations and future directions}

The goodness of the proposed model is moderate. There are at least three possible explanations. Aside from our control variables, such as the level of engagement of Makers in the activities, there is extensive literature discussing how religion (Ellison, 1991), personality (Diener et al., 2003) and, not surprisingly, health (Brief et al., 1993) have a substantial impact on SWB. Collecting these data would have been too intrusive and beyond the scope of this research. A second possible explanation is included in Kafka and Kozma (2002), where they point out that the six-dimensions of the Ryff's scale falls short to represent the whole construct of SWB. Finally, it is worth mentioning that we investigated the antecedents to co-creation excluding makers' final innovative outcome. Understanding the results of a collaborative innovation process would have helped in explaining the specific relations between motives, outcomes and SWB. 
With a relative small sample, we acknowledge that the size of these effects could be biased and therefore we highlight that the results should be independently replicated before jumping to conclusions.

Although the survey method was very effective in giving a picture of the phenomenon's relations, it is weak in explaining the deep psychological processes of what we are aiming to explain. This is why the next steps of research could integrate the previous one taking a more participative and ethnographic approach, not purely observational and descriptive. The study of FabLabs' members should be, therefore, extended with qualitative methods able to clarify attitudes and behaviours. Further research should also be extended to other cultures where the drivers to service co-creation in open innovation contexts could be differently related to SWB from the mechanisms that occurred in Southern Europe.

\section{References}

Abbott, R. A., Ploubidis, G. B., Huppert, F. A., Kuh, D., Wadsworth, M. E. J., \& Croudace, T. J. (2006). Psychometric evaluation and predictive validity of Ryff's psychological well-being items in a UK birth color sample of women. Health and Quality of Life Outcomes, 4(1), 76.

Anderson, L., Ostrom, A.L., Corus, C., Fisk, R.P., Gallan, A.S., Giraldo, M., Mende, M., Mulder, M., Rayburn, S.W., Rosenbaum, M.S., Shirahada, K., \& Williams, J.D. (2013). Transformative service research: An agenda for the future. Journal of Business Research, 66, 1203-1210.

Anseel, F., Lievens, F., Schollaert, E., \& Choragwicka, B. (2010). Response rates in organizational science, 1995-2008: A meta-analytic review and guidelines for survey researchers. Journal of Business and Psychology, 25(3), 335-349.

Argyle, M. (2001). The Psychology of Happiness. Taylor and Francis, New York.

Auh, S., Bell. S., McLeod, C. S. \& Shih, E. (2007). Co-Production and Customer Loyalty in Financial Services. Journal of Retailing, 83(3), 359-370. 
Bardhi, F., \& Eckhardt, G. M. (2012). Access-based consumption: The case of car sharing. Journal of Consumer Research, 39(4), 881-898.

Batra, R., and Ahtola, O.T. (1991). Measuring the Hedonic and Utilitarian Sources of Consumer Attitudes. Marketing Letters, 2(4), 159-170.

Baldwin, C., \& Von Hippel, E. (2011). Modeling a paradigm shift: From producer innovation to user and open collaborative innovation. Organization Science, 22(6), 1399-1417.

Baumeister, R. and Leary, M. R. (1995). The Need to Belong: Desire for Interpersonal Attachments as a Fundamental Human Motivation. Psychological Bullettin, 117(3), 497-529.

Berman, B. (2012). 3-D printing: the third industrial revolution. Business Horizons 55(2), 155-162.

Bettencourt, Lance A. (1997). Customer Voluntary Performance: Customers as Partners in Service Delivery. Journal of Retailing, 73(3), 383-406.

Black, H. G., Vincent, L. H., \& Skinner, S. J. (2014). Customers helping customers: payoffs for linking customers. Journal of Services Marketing, 28(5).

Brief, A. P., Butcher, A. H., George, J. M., \& Link, K. E. (1993). Integrating bottom-up and topdown theories of subjective well-being: the case of health. Journal of personality and social psychology, 64(4), 646.

Burroughs, JE. \& Rindeisch A. (2002). Materialism and well-being: A conflicting values perspective. Journal of Consumer Research, 29, 348-370.

Chesbrough, H. (2003). Open Innovation: The New Imperative for Creating and Profiting from Technology. Harvard Business School Press, Boston.

Clarke, P. J., Marshall, V. W., Ryff, C. D., \& Wheaton, B. (2001). Measuring psychological wellbeing in the Canadian study of health and aging. International Psychogeriatrics, 13(1): 79-90.

Cova, B., Dalli, D. (2009). Working consumers: the next step in marketing theory? Marketing Theory, 9(3), 315-39.

Cova, B., White, T. (2010). Counter-brand and alter-brand communities: the impact of Web 2.0 on tribal marketing approaches. Journal of Marketing Management, 26(3), 256-270. 
Deci, E. L., \& Ryan, R. M. (1985). Intrinsic motivation and self-determination in human behavior. Plenum, New York.

Diener, E. (1984). Subjective well-being. Psychological Bulletin, 95, 542-75.

Diener, E., Suh, E. M., Lucas, R. E., \& Smith, H. L. (1999). Subjective well-being: Three decades of progress. Psychological bulletin, 125(2), 276.

Diener, E., Oishi, S., \& Lucas, R. E. (2003). Personality, culture, and subjective well-being: Emotional and cognitive evaluations of life. Annual review of psychology, 54(1), 403-425.

Dholakia, U. M., \& Bagozzi, R. P. (2004). Motivational antecedents, constituents and consequents of virtual community identity. Godar, S. and S. Pixie-Ferris (Eds.), Virtual and collaborative teams: Process, technologies, and practice: 252-267, IDEA Group, London.

Dolan, P., Peasgood, T., \& White, M. (2008). Do we really know what makes us happy? A review of the economic literature on the factors associated with subjective well-being. Journal of economic psychology, 29(1), 94-122.

Dolan, P., \& Metcalfe, R. (2012). The relationship between innovation and subjective wellbeing. Research Policy, 41(8), 1489-1498.

Ellison, C. G. (1991). Religious involvement and subjective well-being. Journal of health and social behavior, 80-99.

Etgar, M. (2008). A descriptive model of the consumer co-production process. Journal of the Academy of Marketing Science, 36, 97-108.

Feather, N. T. (1992). Values, valences, expectations, and actions. Journal of Social Issues, 48, 109-124.

Franke, N. and Shah, S. (2003). How Communities Support Innovative Activities: An exploration of Assistance and Sharing among End-users. Research Policy, 32(1), 157-78.

Feick, L. and Price, L. (1987), 'The Market Maven: A Diffuser of Marketplace Information. Journal of Marketing, 51(1), 83-97.

Füller, J. (2010). Refining Virtual Co-Creation from a Consumer Perspective. California 22 
Management Review, 52(2), 98-122.

Gershenfeld, N. (2005). Fab: the coming revolution on your desktop - from personal computers to personal fabrication. Basic Books, New York.

Graham, C., \& Nikolova, M. (2013). Does access to information technology make people happier? Insights from well-being surveys from around the world. The Journal of Socio-Economics, 44, 126139.

Grönroos, C. (2011). Value co-creation in service logic: A critical analysis, Marketing Theory, 11, 279-301.

Grönroos, C., \& Voima, P. (2013). Critical service logic: making sense of value creation and cocreation. Journal of the Academy of Marketing Science, 41(2), 133-150.

Guo, L., Arnould, E. J., Gruen, T. W. \& Tang C. (2013). Socializing to Co-Produce: Pathways to Consumers’ Financial Well-Being. Journal of Service Research, 16(4), 549-563.

Heylighen, F. (1992). A cognitive-systemic reconstruction of Maslow's theory of selfactualization. Behavioral Science, 37(1), 39-58.

Ho, J. Y., Dempsey C. (2010). Viral marketing: Motivations to forward online content. Journal of Business Research, 63, 1000-1006.

Janeschek, S., Hottum, P., Kicherer, F., \& Bienzeisler, B. (2013). The dynamics of service productivity and value creation: a service life cycle perspective. The Service Industries Journal, 33(3-4), 366-377.

Judge, T. A., Ilis. R., \& Dimotakis, N. (2010). Are Health and Happiness the Product of Wisdom? The relationship of General Mental Ability to Educational and Occupational Attainment, Health, and SWB. Journal of Applied Psychology, 95(3), 454-468.

Lavasani, M. G., Borhanzadeh, S., Afzali, L., \& Hejazi, E. (2011). The relationship between perceived parenting styles, social support with psychological well-being. Procedia - Social and Behavioral Sciences, 15, 1852-1856. 
Kahneman, D., Krueger, A. B., Schkade, D. A., Schwarz, N., \& Stone, A. A. (2004). A survey method for characterizing daily life experience: The day reconstruction method. Science, 306(5702), 1776-1780.

Kale, S. H. (2004). Spirituality, Religion, and Globalization. Journal of Macromarketing, 24(2), 92107.

Kafka, G.J., Kozma, A. (2002). The Construct Validity of Ryff's Scales of Psychological WellBeing (SPWB) and their Relationship to Measures of Subjective Well-Being. Journal Social Indicators Research, 57(2), 171-190

Karabati, S., \& Cemalcilar, Z. (2010). Values, materialism and well-being: A study with Turkish university students. Journal of Economic Psychology, 31, 624-633.

Kasser, T. (2002). The High Price of Materialism. Mass and London, MIT Press: Cambridge.

Kavetsos, G., \& Koutroumpis, P. (2011). Technological affluence and subjective wellbeing. Journal of economic psychology, 32(5), 742-753.

Keyes, C. L. M., Shmotkin, D., \& Ryff, C. D. (2002). Optimizing well-being: The empirical encounter of two traditions. Journal of Personality and Social Psychology, 82(6), 1007-1022.

Maslow A.H. (1987). Motivation and Personality, 3rd ed., revised by R. Frager, J. Fadiman, C. McReynolds \& R. Cox. Harper and Row, New York.

McKenna, K. Y. A., \& Bargh, J. A. (1999). Causes and consequences of social interaction on the internet: A conceptual framework. Media Psychology, 1, 249-269.

Novak, T. P., Hoffman, D. L. \& Duhachek, A. (2003). The influence of goal-directed and experiential activities in online flow experiences. Journal of Consumer Psychology, 13, 3-16.

Olsen, S.O., \& May, H.T.X. (2013). Consumer Participation: The case of Home Meal Preparation. Psychology and Marketing, 30(1), 1-11.

Osterloh, M, Rota, S. (2007). Open source software development-Just another case of collective invention? Research Policy, 36 (2), 157-171. 
Ostrom, A.L, Bitner, M.J., Brown, S.W., Burkhard, K.A., Goul, M., Smith-Daniels, V., Demirkan, H., \& Rabinovich, E. (2010). Moving Forward and Making a Difference: Research Priorities for the Science of Service. Journal of Service Research, 13(1), 4-36.

Ozanne, J.L., (2011). Introduction to the special issue on transformative consumer research: creating dialogical spaces for policy and action research. Journal of Public Policy \& Marketing, $30(1), 1-4$.

Polo Peña, A. I., Frías Jamilena, D. M., \& Rodríguez Molina, M. Á. (2014). Value co-creation via information and communications technology. The Service Industries Journal, 34(13), 1043-1059.

Rice, T. W., \& Steele, B. J. (2004). Subjective Well-Being and Culture Across Time and Space. Journal of Cross-Cultural Psychology, 35(6), 633-647.

Ryff, C. D. (1989). Happiness is everything, or is it? Explorations on the meaning of psychological SWB. Journal of Personality and Social Psychology, 57(6), 1069-1081.

Ryff, C. D., \& Keyes, C. L. (1995). The structure of psychological well-being revisited. Journal of Personality and Social Psychology, 69(4), 719-727.

Rosenbaum, M.S., Corus, C., Ostrom, A.L., Anderson, L., Fisk, R.P., Gallan, A.S., Giraldo, M., Mende, M., Mulder, M., Rayburn, S. W., Shirahada, K., \& Williams, J.D. (2011) Conceptualization and Aspirations of Transformative Service Research. Journal of Research for Consumers 19, 1-8.

Ruini, C., Ottolini, F., Rafanelli, C., Ryff, C. D., \& Fava, G. A. (2003). La validazione italiana delle Psychological Well-being Scales (PWB). Rivista di psichiatria, 38(3), 117-130.

Sheldon, K. M., Ryan, R. M., Deci, E. L., \& Kasser, T. (2004). The independent effects of goal contents and motives on well-being: It's both what you pursue and why you pursue it. Personality and Social Psychology Bulletin, 30, 475-486.

Sheldon, K. M., Gunz, A., Nichols, C. P. \& Ferguson, Y. (2010). Extrinsic Value Orientation and Affective Forecasting: Overestimating the Rewards, Underestimating the Costs. Journal of Personality, 78(1), 150-178.

Sirigatti, S., Penzo, I., Iani, L., Mazzeschi. A., Hatalskaja, H., Giannetti, E., \& Stefanile, C. (2012). 25 
Measurement Invariance of Ryff's Psychological Well-being Scales Across Italian and Belarusian Students. Social Indicators Research, 1-14.

Troxler, T. (2010). Commons-based Peer-Production of Physical Goods Is there Room for a Hybrid Innovation Ecology? 3rd Free Culture Research Conference, Berlin, 8-9 October.

Vargo, S. L., \& Lusch, R. (2008). Service-dominant logic: continuing the evolution. Journal of the Academy Marketing Science, 36, 1-10.

Vargo, S. L., Maglio, P. P., \& Akaka, M. A. (2008) On value and value co-creation: A service systems and service logic perspective. European Management Journal, 26, 145-152.

von Hippel, E. (2005). Democratizing Innovation. MA: MIT Press, Cambridge.

Woodside, A. G. (2013). Moving beyond multiple regression analysis to algorithms: Calling for adoption of a paradigm shift from symmetric to asymmetric thinking in data analysis and crafting theory. Journal of Business Research, 66, 463-472. 